\title{
Protective effects of oxymatrine against arsenic trioxide- induced liver injury
}

\author{
Li Li ${ }^{1}$, Qinghai Liu ${ }^{1}$, Long Fan ${ }^{1}$, Wei Xiao ${ }^{1}$, Lei Zhao ${ }^{1}$, Yu Wang ${ }^{1}$, Weiguang Ye ${ }^{1}$, Fei \\ Lan $^{1}$, Bin Jia ${ }^{1}$, Hua Feng ${ }^{1}$, Changman Zhou ${ }^{2}$, Xiuqin Yue ${ }^{3}$, Guogang Xing ${ }^{4}$, Tianlong \\ Wang $^{1}$ \\ ${ }^{1}$ Department of Anesthesiology, Xuanwu Hospital, Capital Medical University, Beijing, China \\ ${ }^{2}$ Department of Anatomy \& Histology, School of Basic Medical Sciences, Peking University Health Science Center, Beijing, \\ China \\ ${ }^{3}$ Department of Anesthesiology, the First Affiliated Hospital of Xinxiang Medical University, Henan, China \\ ${ }^{4}$ Department of Neurobiology, School of Basic Medical Sciences, Peking University, Beijing, China \\ Correspondence to: Guogang Xing, email: li_limzk@163.com \\ Tianlong Wang, email: W_tl5595@hotmail.com
}

Keywords: oxymatrine, arsenic trioxide, liver, HO- 1, Nrf-2

Received: July 25, $2016 \quad$ Accepted: September 06, 2016

Published: October 5, 2016

\section{ABSTRACT}

Oxymatrine, a quinolizidine natural drug extracted from Sophora japonica, has been reported to have neuroprotective effect and cardioprotective effect. However, the protective effect of oxymatrine on arsenic trioxide $\left(\mathrm{As}_{2} \mathrm{O}_{3}\right)$-induced liver injury has not been reported. In the present study, we investigated the protective effects of oxymatrine on $\mathrm{As}_{2} \mathrm{O}_{3}$-induced liver injury in rats. Male Wistar rats were administrated $3 \mathrm{mg} / \mathrm{kg} \mathrm{As} \mathrm{O}_{3}$ intravenous injection on alternate days for 4 days. Oxymatrine was given $1 \mathrm{~h}$ before $\mathrm{As}_{2} \mathrm{O}_{3}$ treatment. The results showed that oxymatrine inhibited $\mathrm{As}_{2} \mathrm{O}_{3}$-induced hepatic pathological damage, liver ROS level and MDA level in a dosedependent manner. $\mathrm{As}_{2} \mathrm{O}_{3}$ decreased the antioxidant enzymes SOD, GPX, and CAT activity and the decrease was inhibited by treatment of oxymatrine. Furthermore, oxymatrine attenuated the retention of arsenic in liver tissues and improved the expression of $\mathrm{Nrf2}$ and $\mathrm{HO}-1$. In conclusion, our results suggested that oxymatrine protected against $\mathrm{As}_{2} \mathrm{O}_{3}$-induced oxidative damage by activating $\mathrm{Nrf2/HO-1}$ signaling pathway.

\section{INTRODUCTION}

Arsenic is a hazardous substance of global concern that is present in soil, drinking water, and food [1]. Arsenic often causes severe health hazards such as dermatosis, diabetes, and cancers, despite of its beneficial role in the treatment of acute promyelocytic leukemia (APL) [2, 3]. Studies showed that arsenic affects all organ systems of human and liver is one of the most important target organs for arsenic [4]. Previous reports demonstrated that arsenicinduced liver injury was closely associated with oxidative stress [5]. Arsenic exposure has been reported to produce reactive oxygen species and depress the antioxidant defense system which leading to the oxidative damage of liver tissues [6]. Recently, studies showed that antioxidants had therapeutic effects against arsenic-induced liver injury $[7,8]$. Nrf2 is a redox-sensitive transcription factor that plays a critical role in cellular antioxidant defense [9]. Once stimulation, Nrf2 translocates to the nucleus to initiate transcription of cytoprotective genes such as HO-1 [10]. Studies showed that activation of Nrf2 could protect against arsenic trioxide-induced injury.

Oxymatrine, the major quinolizidine alkaloid isolated from the root of Sophora flavescens Ait (kushen), has been reported to have anti-inflammatory, anti-tumor, and antioxidant effects $[11,12]$. Previous reports showed that oxymatrine exerted a protective effect on ischemia or ischemia/reperfusion damage in liver, intestine and heart $[13,14]$. Oxymatrine has been reported to protect rat brains against permanent focal ischemia [15]. Oxymatrine also protected against experimental hepatic fibrosis [16]. In addition, oxymatrine was found to prevent adriamycininduced cardiac injury in rabbits, which was associated with its antioxidant and anti-apoptotic activities [17]. 
However, the protective effect of oxymatrine against arsenic trioxide-induced liver injury has not been reported. Thus, in the present study, we aimed to investigate the protective effects of oxymatrine against arsenic trioxideinduced liver injury.

\section{RESULTS}

\section{Oxymatrine reduced $\mathrm{As}_{2} \mathrm{O}_{3}$-induced liver histopathologic changes}

The effects of oxymatrine on $\mathrm{As}_{2} \mathrm{O}_{3}$-induced liver histopathologic changes were detected in this study. The results showed that liver tissues of control and oxymatrinetreated groups showed normal lobular architecture and cellular structure. Liver sections of $\mathrm{As}_{2} \mathrm{O}_{3}$-treated group showed significant pathologic changes, such as extensive areas of portal inflammation, inflammatory cell infiltration and cellular necrosis. However, the pathological changes of liver sections were attenuated in $\mathrm{As}_{2} \mathrm{O}_{3}+$ oxymatrine $(12.5,25,50 \mathrm{mg} / \mathrm{kg}$ ) treated group (Figure 1).

\section{Effects of oxymatrine on $\mathrm{As}_{2} \mathrm{O}_{3}$-induced antioxidant enzymes SOD, GPX, and CAT activity}

The effects of oxymatrine on $\mathrm{As}_{2} \mathrm{O}_{3}$-induced antioxidant enzymes SOD, GPX, and CAT activity was shown in Figure 2. The results showed that compared to the control group and oxymatrine-treated group, the levels of SOD, GPX, and CAT decreased significantly in $\mathrm{As}_{2} \mathrm{O}_{3}$ - treated group. However, the inhibition of SOD, GPX, and CAT levels by $\mathrm{As}_{2} \mathrm{O}_{3}$-was revised by treatment of oxymatrine $(12.5,25,50 \mathrm{mg} / \mathrm{kg})$.

\section{Effects of oxymatrine on $\mathrm{As}_{2} \mathrm{O}_{3}$-induced ROS and MDA levels}

The effects of oxymatrine on $\mathrm{As}_{2} \mathrm{O}_{3}$-induced ROS and MDA levels were shown in Figure 3 . The results showed that ROS and MDA levels increased significantly in $\mathrm{As}_{2} \mathrm{O}_{3}$-treated group in comparison with control group. However, the levels of ROS and MDA in $\mathrm{As}_{2} \mathrm{O}_{3}+$ oxymatrine $(12.5,25,50 \mathrm{mg} / \mathrm{kg})$ treated group decreased significantly in comparison with $\mathrm{As}_{2} \mathrm{O}_{3}$-treated group.

\section{Effects of oxymatrine on $\mathrm{As}_{2} \mathrm{O}_{3}$-induced ALT and AST levels in serum}

The effects of oxymatrine on $\mathrm{As}_{2} \mathrm{O}_{3}$-induced ALT and AST levels were shown in Figure 4. As shown in Figure 4, the levels of ALT and AST of $\mathrm{As}_{2} \mathrm{O}_{3}$-treated group increased significantly than that of control group. However, the levels of ALT and AST in $\mathrm{As}_{2} \mathrm{O}_{3}+$ oxymatrine $(12.5,25,50 \mathrm{mg} / \mathrm{kg})$ treated group decreased significantly in comparison with $\mathrm{As}_{2} \mathrm{O}_{3}$-treated group.

\section{Effects of oxymatrine on As accumulation in liver tissues}

The results showed that compared to the control group, $\mathrm{As}_{2} \mathrm{O}_{3}$ resulted in a significant increase in the arsenic concentration of liver tissues. However, treatment
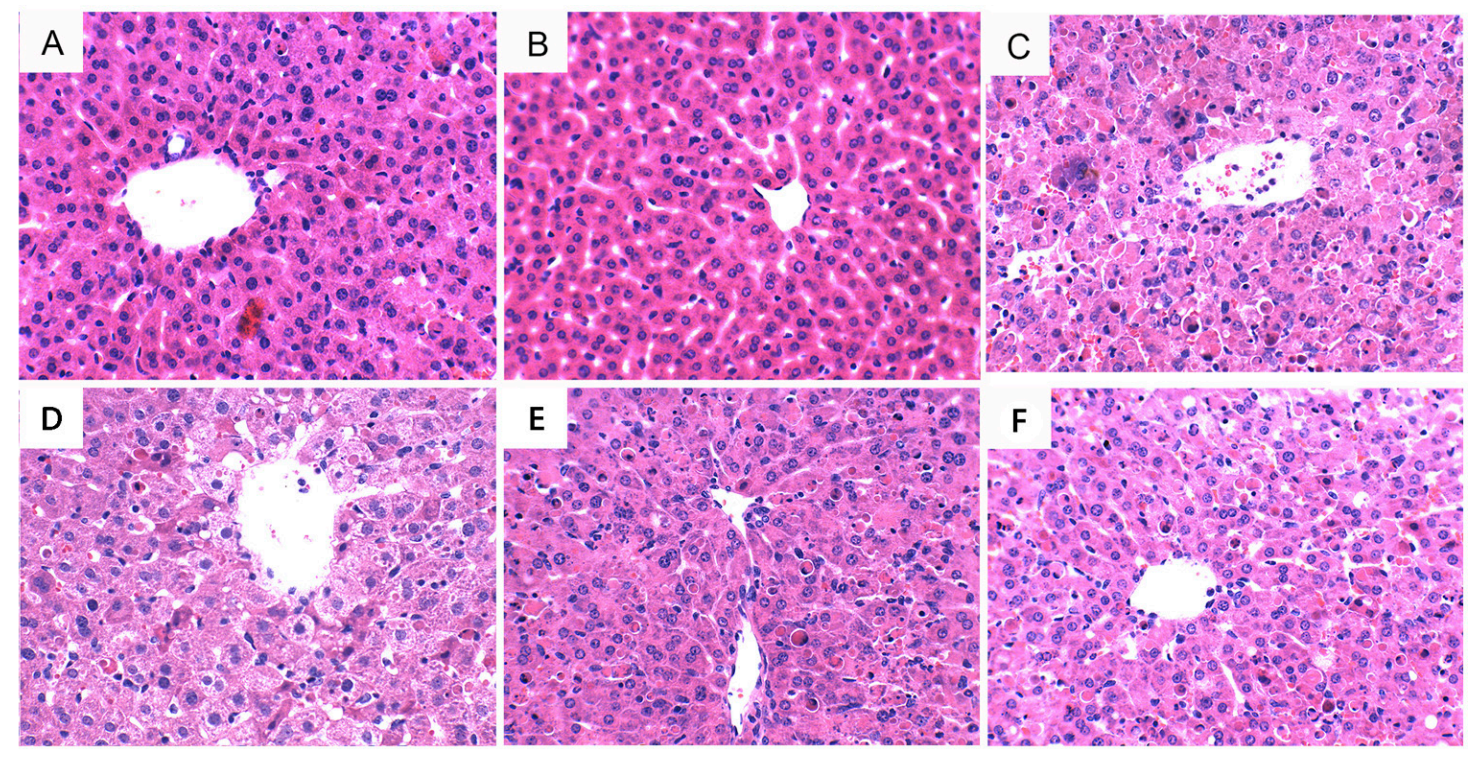

Figure 1: Effects of oxymatrine on $\mathrm{As}_{2} \mathrm{O}_{3}$-induced liver histopathologic changes. Representative histological changes of liver obtained from mice of different groups. A. Control group, B. Oxymatrine $(50 \mathrm{mg} / \mathrm{kg})$ group, $\mathbf{C}$. $\mathrm{As}_{2} \mathrm{O}_{3}$ group, D. Oxymatrine $+\mathrm{As}_{2} \mathrm{O}_{3}$ $\left(12.5 \mathrm{mg} / \mathrm{kg}\right.$ ) group, E. Oxymatrine $+\mathrm{As}_{2} \mathrm{O}_{3}\left(25 \mathrm{mg} / \mathrm{kg}\right.$ ) group, F. Oxymatrine $+\mathrm{As}_{2} \mathrm{O}_{3}(50 \mathrm{mg} / \mathrm{kg})$ group (Hematoxylin and eosin staining, magnification $200 \times$ ). 

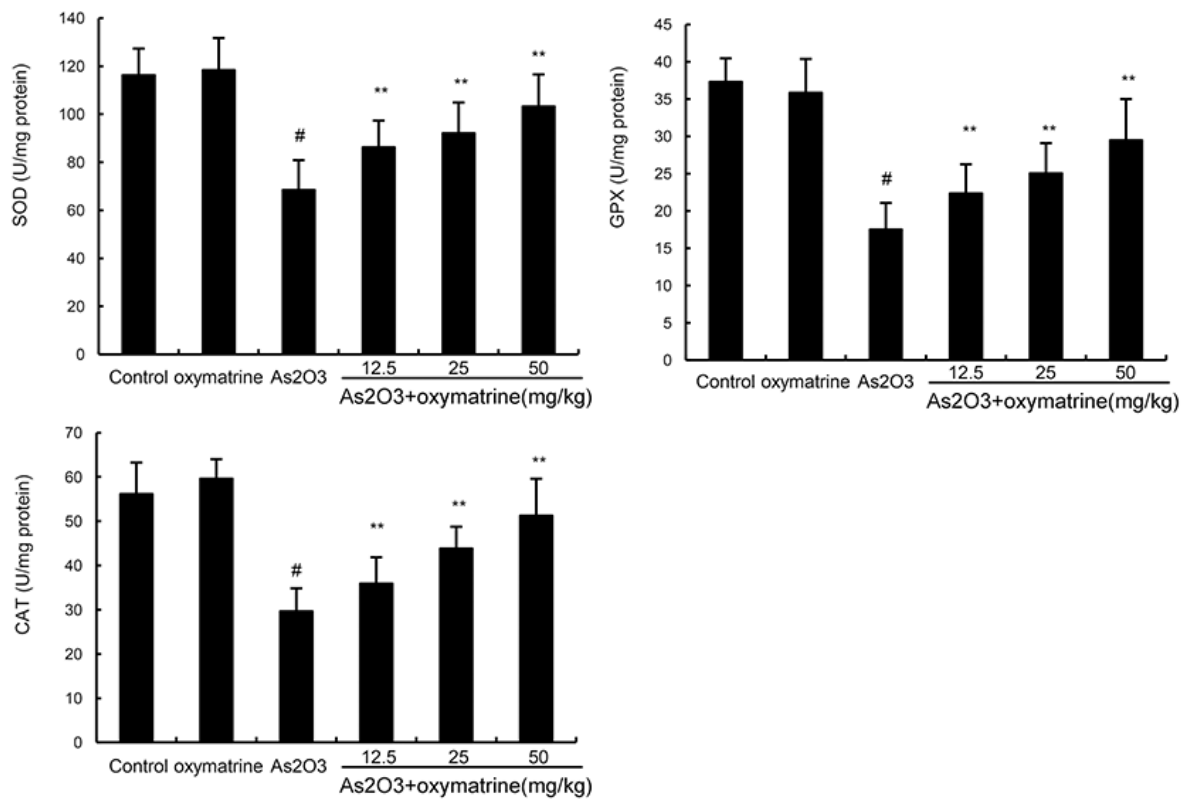

Figure 2: Effects of oxymatrine on $\mathrm{As}_{2} \mathrm{O}_{3}$-induced antioxidant enzymes SOD, GPX, and CAT activity. The values presented are the mean $\pm \operatorname{SEM}\left(\mathrm{n}=12\right.$ in each group). $\mathrm{p} \#<0.01$ vs. control group, $\mathrm{p}^{*}<0.05, \mathrm{p}^{* *}<0.01 \mathrm{vs} . \mathrm{As}_{2} \mathrm{O}_{3}$ group.
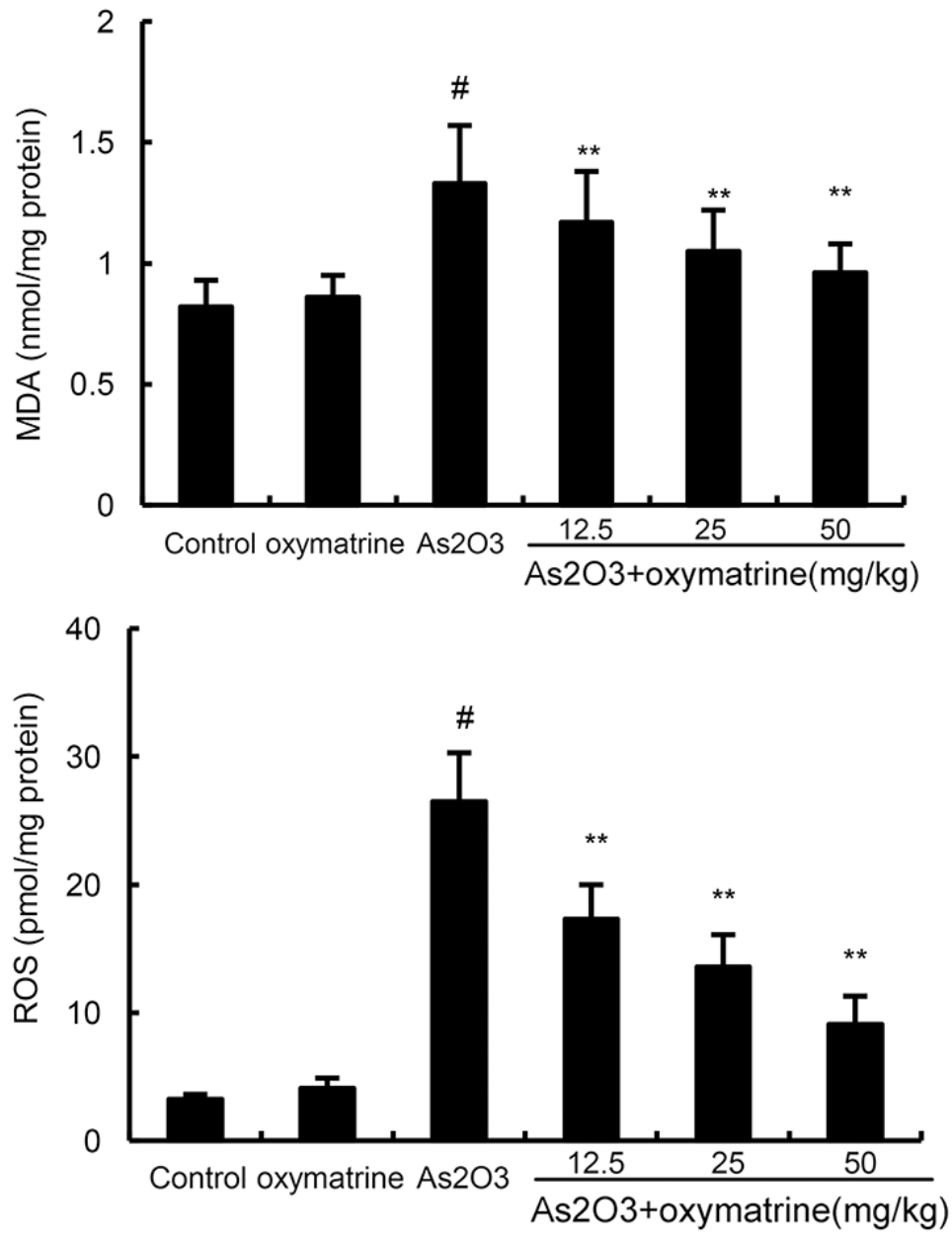

Figure 3: Effects of oxymatrine on $\mathrm{As}_{2} \mathrm{O}_{3}$-induced ROS and MDA levels. The values presented are the means $\pm \mathrm{SEM}(\mathrm{n}=12 \mathrm{in}$ each group). $\# \mathrm{p}<0.01$ vs. control group, ${ }^{*} \mathrm{p}<0.05$ and ${ }^{* *} \mathrm{p}<0.01$ vs. $\mathrm{As}_{2} \mathrm{O}_{3}$ group. 
of oxymatrine $(12.5,25,50 \mathrm{mg} / \mathrm{kg})$ significantly attenuated $\mathrm{As}_{2} \mathrm{O}_{3}$-induced accumulation of arsenic in liver tissues (Figure 5).

\section{Effects of oxymatrine on Nrf2 and HO-1 expression}

The effects of oxymatrine on Nrf2 and HO-1 expression were detected by Western blot analysis. As shown in Figure 6, $\mathrm{As}_{2} \mathrm{O}_{3}$ treatment increased the expression of Nrf2 and HO-1. However, oxymatrine (12.5, $25,50 \mathrm{mg} / \mathrm{kg}$ ) up-regulated the expression of $\mathrm{Nrf2}$ and $\mathrm{HO}-1$ induced by $\mathrm{As}_{2} \mathrm{O}_{3}$.

\section{DISCUSSION}

Oxymatrine, a quinolizidine natural drug extracted from Sophora japonica, has been reported to have antioxidant effect [12]. In the present study, we investigate the protective effects of oxymatrine on $\mathrm{As}_{2} \mathrm{O}_{3}$-induced toxicity in liver and oxidative stress in rats. The results showed that oxymatrine exhibited protective effects on $\mathrm{As}_{2} \mathrm{O}_{3}$-induced liver injury. Oxymatrine protected against $\mathrm{As}_{2} \mathrm{O}_{3}$-induced liver injury through activating $\mathrm{Nrf} 2$ signaling pathway.

Serum AST and ALT were used as biochemical indicator of liver injury $[18,19]$. Our results showed that the levels of AST and ALT increased significantly in rats exposure to $\mathrm{As}_{2} \mathrm{O}_{3}$ Elevated levels of serum AST and ALT in $\mathrm{As}_{2} \mathrm{O}_{3}$-treated rats were associated with the extensive alterations in the pathological changes of liver tissues. Treatment of oxymatrine remarkably inhibited $\mathrm{As}_{2} \mathrm{O}_{3}$-induced AST and ALT production which suggesting oxymatrine could attenuate liver damage. Meanwhile, histological analysis demonstrated that oxymatrine attenuated liver pathologic changes, including inflammatory cell infiltration and cellular necrosis. These results indicated oxymatrine had protective effects against $\mathrm{As}_{2} \mathrm{O}_{3}$-induced liver injury.

Previous studies showed that $\mathrm{As}_{2} \mathrm{O}_{3}$-induced liver injury is associated with increased oxidative stress in liver tissues [20]. Arsenic exposure could induce
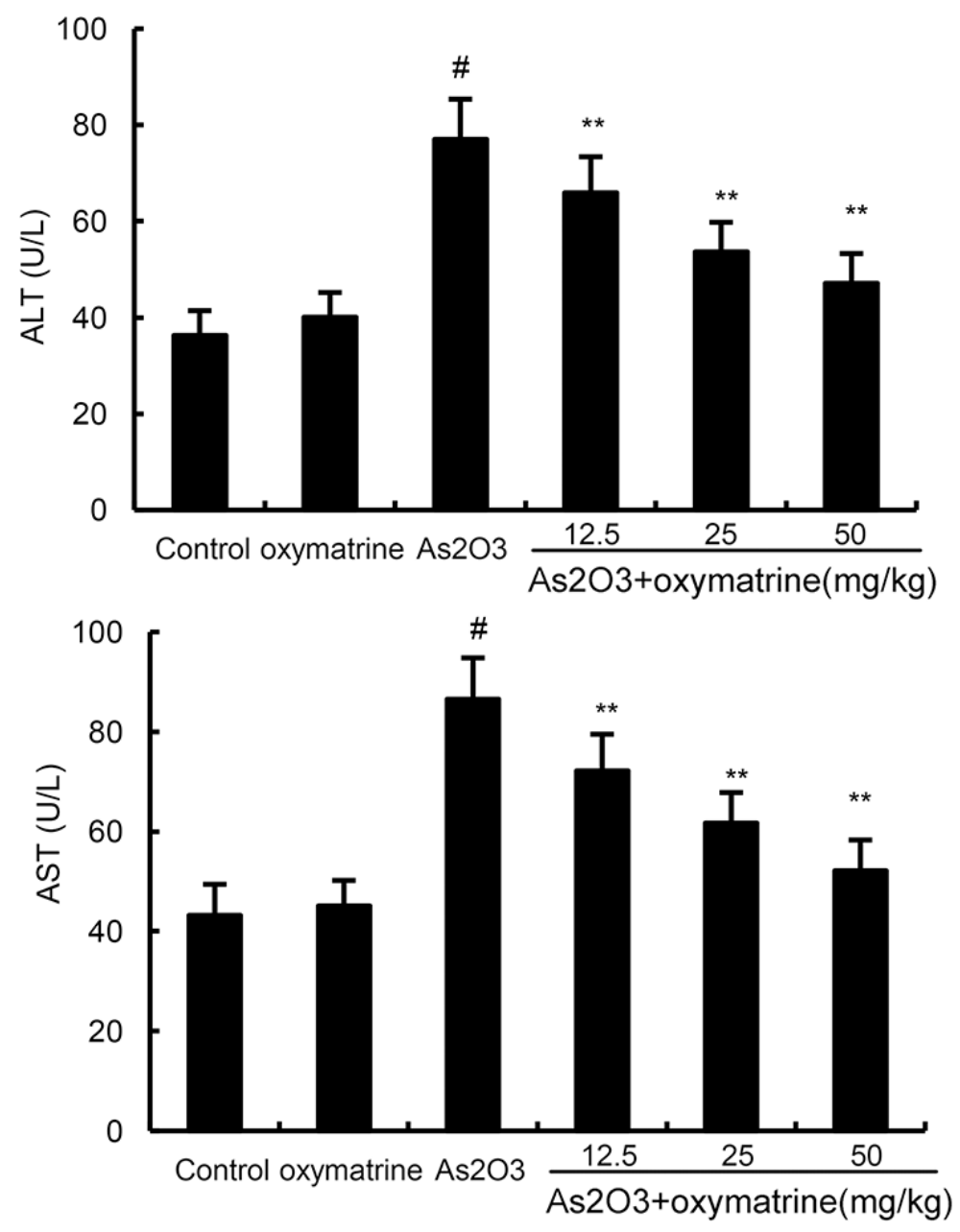

Figure 4: Effects of oxymatrine on $\mathrm{As}_{2} \mathrm{O}_{3}$-induced ALT and AST levels. The values presented are the means \pm SEM ( $\mathrm{n}=12$ in each group). $\# \mathrm{p}<0.01$ vs. control group, ${ }^{*} \mathrm{p}<0.05$ and ${ }^{* *} \mathrm{p}<0.01$ vs. $\mathrm{As}_{2} \mathrm{O}_{3}$ group. 

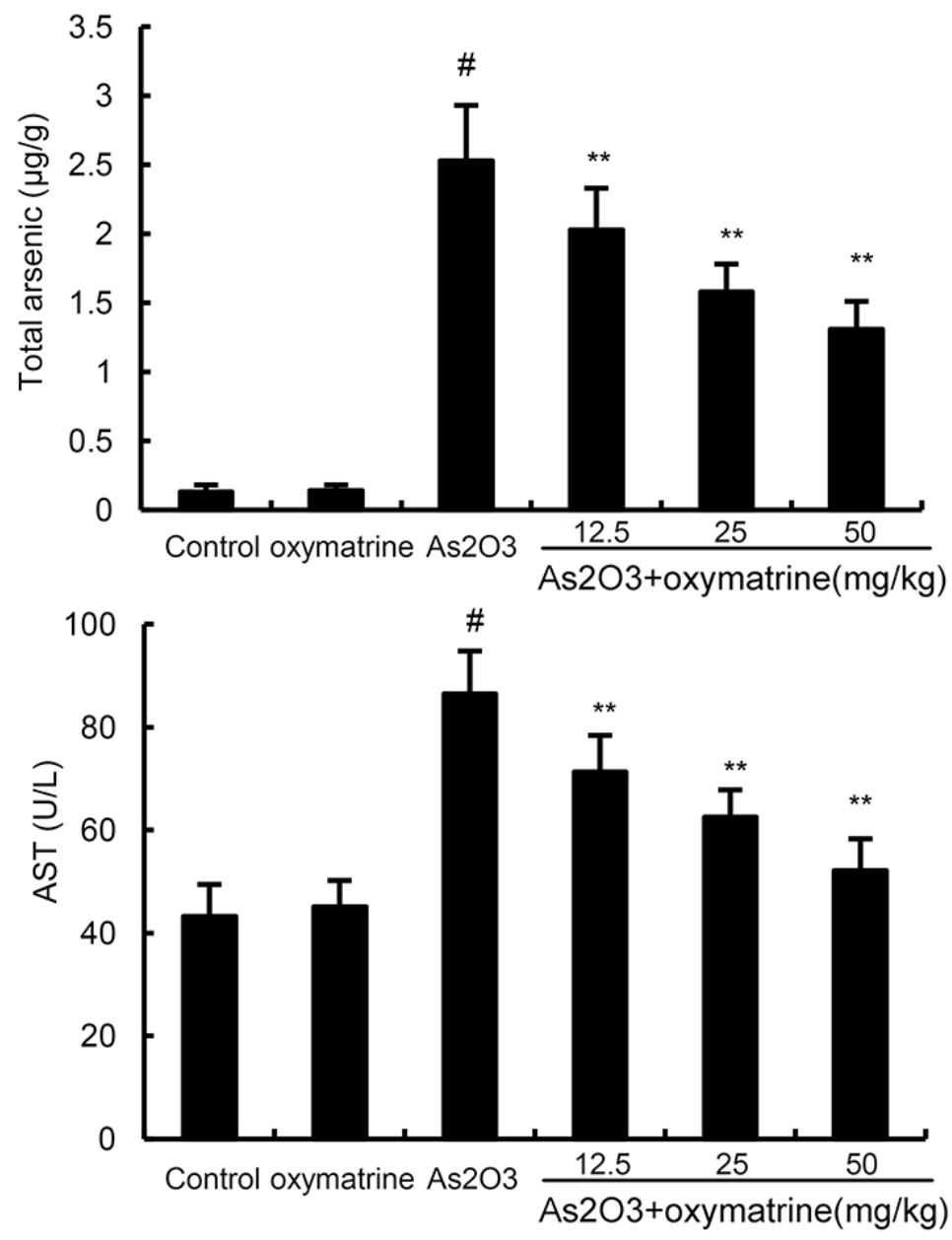

Figure 5: Effects of oxymatrine on As accumulation in liver tissues. The values presented are the means \pm SEM ( $\mathrm{n}=12$ in each group). $\# \mathrm{p}<0.01$ vs. control group, $* \mathrm{p}<0.05$ and $* * \mathrm{p}<0.01$ vs. $\mathrm{As}_{2} \mathrm{O}_{3}$ group.
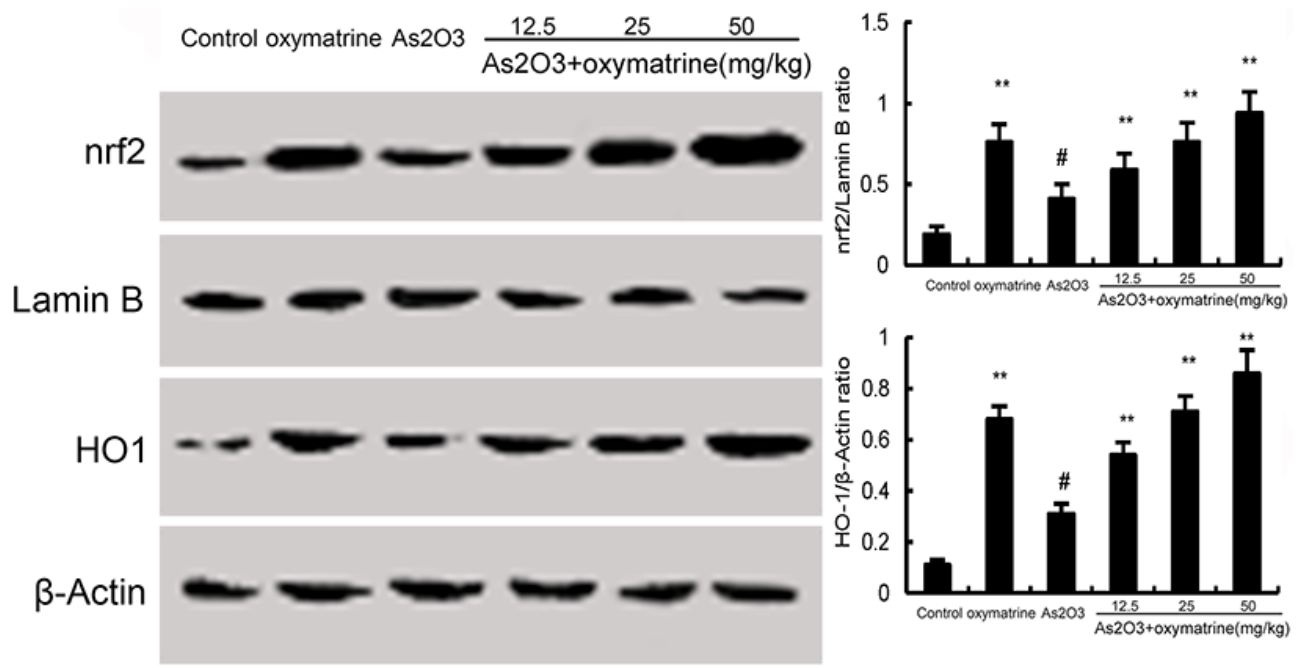

Figure 6: Effects of oxymatrine on Nrf2 and HO-1 expression. The values presented are the means $\pm \mathrm{SEM}$ ( $\mathrm{n}=12 \mathrm{in}$ each group). $\# \mathrm{p}<0.01$ vs. control group, ${ }^{*} \mathrm{p}<0.05$ and $* * \mathrm{p}<0.01$ vs. $\mathrm{As}_{2} \mathrm{O}_{3}$ group. 
the production of ROS which played critical roles in arsenic-induced toxicity $[21,22]$. Lipid peroxidation generates a variety of relatively stable decomposition end-products, such as MDA, which can be measured as indirect indicators of oxidative stress [23]. In this study, we found that the levels of ROS and MDA in liver tissues increased after $\mathrm{As}_{2} \mathrm{O}_{3}$ exposure. Treatment of oxymatrine significantly inhibited $\mathrm{As}_{2} \mathrm{O}_{3}$-induced ROS and MDA production. Arsenic-induced damage in the antioxidant system involves several mechanisms such as altered SOD, CAT and GPX expression [24]. In this study, our results showed that the inhibition of SOD, GPX, and CAT levels by $\mathrm{As}_{2} \mathrm{O}_{3}$-was abolished by treatment of oxymatrine. These results indicated that oxymatrine exhibited antioxidant effects in $\mathrm{As}_{2} \mathrm{O}_{3}$-induced liver injury. Nrf-2 has been reported to play important roles in the induction of antioxidant enzymes against oxidative stress [25, 26]. HO-1 expression is controlled by the transcription factor Nrf-2 [27]. Recent studies showed that Nrf-2 signaling pathway played a protective role in $\mathrm{As}_{2} \mathrm{O}_{3}$-induced liver injury [28]. Our results showed that the increases in Nrf2 and HO-1 expression were augmented by oxymatrine.

In conclusion, the present study demonstrated that oxymatrine attenuated $\mathrm{As}_{2} \mathrm{O}_{3}$-induced oxidative damage in liver tissues by activating Nrf2/HO-1 signaling pathway. Oxymatrine may be an agent for preventing and treating $\mathrm{As}_{2} \mathrm{O}_{3}$-induced liver injury.

\section{MATERIALS AND METHODS}

\section{Reagents}

Oxymatrine (purity $>98 \%$ ) was purchased from Beijing SL Pharmaceutical Co., Ltd. (Beijing, China). $\mathrm{As}_{2} \mathrm{O}_{3}$ parenteral solution $(10 \mathrm{mg} / \mathrm{ml})$ was purchased from Harbin Yida Pharmaceutical Company Ltd. (Harbin, China). GPX, SOD, CAT, and MDA determination kits were provided by the Jiancheng Bioengineering Institute of Nanjing (Nanjing, Jiangsu, China). Antibodies specific for Nrf2, HO-1, Lamin B, and $\beta$-actin were purchased from Cell Signaling Technology Inc (Beverly, MA). All other chemicals were of reagent grade.

\section{Animals}

Seventy-two healthy male Wistar rats (110-130 g) were purchased from the Center of Experimental Animals of Shandong University (Shangdong, China). The rats were housed under standard conditions (temperature, $23 \pm 2{ }^{\circ} \mathrm{C}$; humidity: $60 \pm 5 \%$ ). The rats were acclimatized to the environment for 6 days prior to the experiments. The rats had free access to water and food. All animal experiments carried out in this study were approved by the NIH Guide for the Care and Use of Laboratory Animals.

\section{Experimental protocol}

A total of 72 rats were randomly divided into six groups ( $\mathrm{n}=12$ each group): normal control group, oxymatrine $(50 \mathrm{mg} / \mathrm{kg})$ treatment group, $\mathrm{As}_{2} \mathrm{O}_{3}$ exposure group, and $\mathrm{As}_{2} \mathrm{O}_{3}+$ oxymatrine $(12.5,25,50 \mathrm{mg} / \mathrm{kg}$ ) treatment group. In control group, rats were given equal amount of $0.9 \%$ normal saline. In oxymatrine treatment group, rats were given by an intraperitoneal injection of oxymatrine $(50 \mathrm{mg} / \mathrm{kg})$. In the $\mathrm{As}_{2} \mathrm{O}_{3}$ exposure group, rats were administrated $3 \mathrm{mg} / \mathrm{kg} \mathrm{As} \mathrm{O}_{3}$ intravenous injection on alternate days for 4 days. In $\mathrm{As}_{2} \mathrm{O}_{3}+$ oxymatrine treatment group, rats were given by an intraperitoneal injection of oxymatrine $(12.5,25,50 \mathrm{mg} / \mathrm{kg}) 1 \mathrm{~h}$ before $\mathrm{As}_{2} \mathrm{O}_{3}$ administered. On the 8th day, rats were killed and the blood samples and livers from each group were collected for various biochemical analyses.

\section{Histological analysis}

The liver tissues were collected and fixed in $10 \%$ formalin. The liver tissues were dehydrated, embedded in paraffin, and sliced at $4 \mu \mathrm{M}$ thickness. Then, the sections were stained with hematoxylin and eosin (H\&E) reagent and visualized with a microscope (Olympus, Japan).

\section{Analysis of oxidative stress and antioxidant defense}

Liver MDA and ROS level, the antioxidant enzymes SOD, GPX, and CAT activity were detected by using commercial kits purchased from the Jiancheng Bioengineering Institute of Nanjing (Nanjing, Jiangsu, China).

\section{Blood clinical analyses}

Blood samples were collected and centrifuged at $3000 \mathrm{~g}$ for $8 \mathrm{~min}$ to obtain serum. The ALT and AST levels were measured using test kits purchased from the Jiancheng Bioengineering Institute of Nanjing (Nanjing, Jiangsu, China).

\section{Determination of total arsenic in the liver}

The liver tissue was digested in $\mathrm{HNO}_{3}-\mathrm{HCLO}_{4}$ solution for $48 \mathrm{~h}$ at $130^{\circ} \mathrm{C}$. Then the digested samples were diluted with deionized water. The concentrations of arsenic were detected using atomic fluorescence spectrometry.

\section{Western blot analysis}

Proteins of liver tissues were extracted using T-PER Tissue Protein Extraction Reagent Kit according to the manufacturer's instructions (Thermo). The protein concentration was determined through BCA method. 40 
$\mu \mathrm{g}$ proteins were separated on $10 \%$ SDS-PAGE gel and transferred onto PVDF membranes. After blocking with $5 \%$ skim milk for $2 \mathrm{~h}$, the membranes were incubated with the specific primary antibodies Nrf-2 (1: 1000), HO-1 (1: $1000)$ at $4{ }^{\circ} \mathrm{C}$ overnight. After washing three times, the membranes were probed with HRP-conjugated secondary antibody at room temperature for $2 \mathrm{~h}$. Blots were then developed with the ECL Plus Western Blotting Detection System (Amersham Life Science, UK).

\section{Statistical analysis}

The results are expressed as the mean \pm SEM of three independent experiments. For comparison among groups were determined by one-way ANOVA followed by the Tukey post-hoc test. The $\mathrm{P}<0.05$ was considered statistically significant.

\section{CONFLICTS OF INTEREST}

The authors have no conflict of interest to declare.

\section{GRANT SUPPORT}

This work was supported by National Natural Science Foundation of China No. 81500996 to LL, and 31271280 to $\mathrm{CZ}$ and 81371237 to GX, Beijing Municipal Administration of Hospitals' Ascent Plan (DFL 20150802) to TW, Health Science and Technology in Henan Province innovative young engineering talent technological innovation funded projects No.20114155 to XY, Beijing Postdoctoral Research Foundation (2015) to LL.

\section{REFERENCES}

1. Duxbury JM, Mayer AB, Lauren JG and Hassan N. Food chain aspects of arsenic contamination in Bangladesh: Effects on quality and productivity of rice. J Environ Sci Heal A. 2003;38:61-69.

2. Cohen MH, Hirschfeld S, Honig SF, Ibrahim A, Johnson JR, O'Leary JJ, White RM, Williams GA and Pazdur R. Drug approval summaries: Arsenic trioxide, tamoxifen citrate, anastrazole, paclitaxel, bexarotene. Oncologist. 2001;6:4-11.

3. Lazo G, Cortes J, O'Brien S, Estey E, Thomas D and Kantarjian H. Use of arsenic trioxide (As2O3) in the treatment of acute promyelocytic leukemia (APL). The MD Anderson experience. Blood. 2001;98:595a-596a.

4. Liu J and Waalkes MP. Liver is a target of arsenic carcinogenesis. Toxicol Sci. 2008;105:24-32.

5. Flora SJS. Arsenic-induced oxidative stress and its reversibility. Free Radical Bio Med. 2011;51:257-281.

6. Ghosh A, Mandal AK, Sarkar S, Panda S and Das N. Nanoencapsulation of quercetin enhances its dietary efficacy in combating arsenic-induced oxidative damage in liver and brain of rats. Life sciences. 2009;84:75-80.

7. Gupta R, Kannan GM, Sharma M and SJ SF. Therapeutic effects of Moringa oleifera on arsenic-induced toxicity in rats. Environmental toxicology and pharmacology. 2005;20:456-464.

8. Flora SJ, Mehta A and Gupta R. Prevention of arsenicinduced hepatic apoptosis by concomitant administration of garlic extracts in mice. Chemico-biological interactions. 2009; 177:227-233.

9. Li W, Khor TO, Xu C, Shen G, Jeong W-S, Yu S and Kong A-N. Activation of Nrf2-antioxidant signaling attenuates NF $\kappa$ B-inflammatory response and elicits apoptosis. Biochemical pharmacology. 2008;76:1485-1489.

10. Li N, Alam J, Venkatesan MI, Eiguren-Fernandez A, Schmitz D, Di Stefano E, Slaughter N, Killeen E, Wang $\mathrm{X}$ and Huang A. Nrf2 is a key transcription factor that regulates antioxidant defense in macrophages and epithelial cells: protecting against the proinflammatory and oxidizing effects of diesel exhaust chemicals. The Journal of Immunology. 2004;173:3467-3481.

11. Zhang Y, Piao B, Zhang Y, Hua B, Hou W, Xu W, Qi X, Zhu X, Pei Y and Lin H. Oxymatrine diminishes the side population and inhibits the expression of beta-catenin in MCF-7 breast cancer cells. Medical oncology. 2011;28 :S99-107.

12. Li M, Zhang XJ, Cui LL, Yang R, Wang LN, Liu LL and $\mathrm{Du}$ W. The Neuroprotection of Oxymatrine in Cerebral Ischemia/Reperfusion Is Related to Nuclear Factor Erythroid 2-Related Factor 2 (Nrf2)-Mediated Antioxidant Response: Role of Nrf2 and Hemeoxygenase-1 Expression. Biological \& pharmaceutical bulletin. 2011;34:595-601.

13. Jiang H, Meng F, Li J and Sun X. Anti-apoptosis effects of oxymatrine protect the liver from warm ischemia reperfusion injury in rats. World journal of surgery. 2005;29:1397-1401.

14. Zhao J, Yu S, Tong L, Zhang F, Jiang X, Pan S, Jiang H and Sun $\mathrm{X}$. Oxymatrine attenuates intestinal ischemia/ reperfusion injury in rats. Surgery today. 2008;38:931-937.

15. Liu Y, Zhang XJ, Yang CH and Fan HG. Oxymatrine protects rat brains against permanent focal ischemia and downregulates NF-kappaB expression. Brain Res. 2009;1268:174-180.

16. Shi GF and Li Q. Effects of oxymatrine on experimental hepatic fibrosis and its mechanism in vivo. World journal of gastroenterology. 2005;11:268-271.

17. Runtao G, Guo D, Jiangbo Y, Xu W and Shusen Y. Oxymatrine, the main alkaloid component of Sophora roots, protects heart against arrhythmias in rats. Planta medica. 2011;77:226-230.

18. Kim WR, Flamm SL, Di Bisceglie AM, Bodenheimer HC and A PPCA. Serum activity of alanine aminotransferase (ALT) as an indicator of health and disease. Hepatology. 2008;47:1363-1370. 
19. Smith J, Rao S, Jovanovic B and Flamm SL. AST : ALT ratio $>1$ predicts increased fibrosis stage but is not an accurate predictor of advanced fibrosis/cirrhosis in patients with chronic hepatitis $\mathrm{C}$ virus (HCV) infection. Gastroenterology. 2000;118:A974-A975.

20. Wu J, Liu J, Waalkes MP, Cheng ML, Li L, Li CX and Yang Q. High dietary fat exacerbates arsenic-induced liver fibrosis in mice. Exp Biol Med. 2008;233:377-384.

21. Liu L, Trimarchi JR, Navarro P, Blasco MA and Keefe DL. Oxidative stress contributes to arsenic-induced telomere attrition, chromosome instability, and apoptosis. J Biol Chem. 2003;278:31998-32004.

22. Shi HL, Shi XL and Liu KJ. Oxidative mechanism of arsenic toxicity and carcinogenesis. Mol Cell Biochem. 2004;255:67-78.

23. Halliwell B and Chirico S. Lipid peroxidation: its mechanism, measurement, and significance. The American journal of clinical nutrition. 1993;57:715S-724S; discussion 724S-725S.

24. Sharma A, Sharma MK and Kumar M. Modulatory role of Emblica officinalis fruit extract against arsenic induced oxidative stress in Swiss albino mice. Chemico-biological interactions. 2009;180:20-30.

25. Lee JM and Johnson JA. An important role of Nrf2-ARE pathway in the cellular defense mechanism. Journal of biochemistry and molecular biology. 2004;37:139-143.

26. Yanaka A, Zhang S, Tauchi M, Suzuki H, Shibahara T, Matsui H, Nakahara A, Tanaka N and Yamamoto M. Role of the nrf-2 gene in protection and repair of gastric mucosa against oxidative stress. Inflammopharmacology. 2005;13:83-90.

27. Kusunoki C, Yang L, Yoshizaki T, Nakagawa F, Ishikado A, Kondo M, Morino K, Sekine O, Ugi S, Nishio Y, Kashiwagi A and Maegawa H. Omega-3 polyunsaturated fatty acid has an anti-oxidant effect via the $\mathrm{Nrf}-2 / \mathrm{HO}-1$ pathway in 3T3-L1 adipocytes. Biochemical and biophysical research communications. 2013;430:225-230.

28. De Vizcaya-Ruiz A, Barbier O, Ruiz-Ramos R and Cebrian ME. Biomarkers of oxidative stress and damage in human populations exposed to arsenic. Mutat Res-Gen Tox En. 2009;674:85-92. 